\title{
Yang Yuelin and Modern Sizing Technology in China
}

\author{
Wen Zhang ${ }^{1} \&$ Xiaoming Yang ${ }^{2}$ \\ ${ }^{1}$ College of Humanities, Donghua University, Songjiang, Shanghai, China \\ Correspondence: Xiaoming Yang, College of humanities, Donghua University, Songjiang, Shanghai, 201620, \\ China. E-mail: ynide@sina.com \\ Foudation item: The year 2018-2019 Fundamental Research Funds for the Central Universities and Graduate \\ Student Innovation Fund of Donghua University "Research on the development of sizing technology in China " \\ (Project No., CUSF-DH-D-2019105) stage of achievements.
}

Received: December 16, 2019

Accepted: December 28, 2019

Online Published: January 31, 2020

doi:10.5539/ass.v16n2p51

URL: https://doi.org/10.5539/ass.v16n2p51

\begin{abstract}
Since modern times, China has been forced into the huge wave of world industrialization. Yang Yuelin, a famous textile engineering expert and educator, is one of the countless people with lofty ideals who want to serve the country and embark on the road of "saving the country through industry". Yang Yuelin wrote a book "theoretical and practical sizing theory" after he learned the sizing technology of China and the West. The sizing principles summarized in the book constitute the theoretical basis of "sizing working method" of Qingdao Textile administration, which has a great driving role for sizing work in China. In the early days of the founding of the people's Republic of China, Yang Yuelin also actively responded to the call of the state and actively participated in the summary and promotion of the "Hao Jianxiu spinning method", which greatly encouraged the enthusiasm of the textile workers and their enthusiasm for production.
\end{abstract}

Keywords: Yang Yuelin, sizing technology

Textile industry is an important pillar industry of China's national economy. Since modern times, a series of collisions have taken place between the traditional handicraft textile industry in ancient China and the machine textile industry in the West. In order to keep up with the pace of the world, China has done a lot of work in modern times to adapt to the machine textile industry. Sizing, as an important process in machine textile industry, has also been paid attention to, and Yang Yuelin is the leader of sizing industry in modern China. After returning to Japan, Yang Yuelin firmly embarked on the road of "saving the country by industry". Through translating and learning foreign excellent works and his own many years of practical experience, he wrote the book "theoretical and practical sizing studies", which promoted the sizing industry in China to a new level. Therefore, the research on Yang Yuelin's contribution to sizing technology is of great significance to the development of China's modern textile industry and can greatly enrich the research content of the internal history of China's modern textile technology history.

\section{Yang Yuelin's Contribution to Sizing Technology}

\subsection{About Yang Yuelin}

Yang Yuelin had excellent academic performance when he was young, and served as a mathematics teacher after graduation. But at that time, China, surrounded by the powers, was left with only the last breath, which made Yang Yuelin, who had the heart to save the national conditions, very sad. After his brother went abroad to study in Japan, Yang Yuelin resolutely quit his teaching post and went on the road of "saving the country by industry". Yang Yuelin studied in the textile department of Tokyo Institute of technology on the date after he was admitted to study abroad at public expense. This school is the predecessor of Tokyo Institute of technology. In the ranking of times Asian University in 2018, this school is in the 33rd place. It can be seen that Yang Yuelin has achieved outstanding results and worked hard.

In March 1924, Yang Yuelin graduated from Tokyo University of technology. He was introduced by the Japanese and Chinese society to practice in the Tokyo Wool Manufacturing Institute. One year later, he returned to the motherland and worked as an engineer in the East three provinces' wool factory. During this period, he focused on practice and accumulated experience, combining his knowledge with practice to a great extent. In the 1920s and 1930s, there were constant internal and external troubles, and even the situation that Wuxi Zhenxin yarn 
factory, where Yang Yuelin once worked, was closed. However, none of this can stop the engineer's road of industrial salvation. In 1927, Yang Yuelin went to Japan to practice in Nagasaki Co., Ltd. with the problems encountered in textile production. In 1928, he returned to Shanghai, worked as an engineer in Shenxin No.2 factory, and then transferred as an engineer in Shenxin No.7 factory. Because he spare no effort to work day and night, in 1929, he was tired of lung disease and hematemesis, and went to Wuxi for treatment. He recovered in the summer of 1932. Invited by Jiang zheqing, manager of Zhenxin yarn factory, he was appointed deputy director of Zhenxin cloth factory and presided over the preparation of cloth factory. Under the difficult conditions of financial and material resources shortage, it took only one year to build and put into production, and soon created a "daily interest" brand, which won the market and honor for China's national industry.

In July 1936, Yang Yuelin was appointed as the weaving engineer of Shanghai Hengfeng yarn factory. In 1937, Tong Runfu was appointed Commissioner of the cotton industry control committee of the National Economic Commission. In August 1938, he was appointed as the Commissioner of Chengfu company and then promoted to the chief of planning section of Public Works Department.

In August 1945, the Anti Japanese war was won. In January 1946, Yang Yuelin was invited by fan Chengchuan, manager of Qingdao Branch of China Textile Corporation to receive Japanese and foreign cotton yarn factories (renamed as China Textile Qingdao No.2 factory after receiving) in Qingdao, and served as resident engineer and director of China Textile Qingdao No.2 factory. In January 1947, he was promoted to chief engineer and deputy manager of China Textile Qingdao Branch. In January 1951, he was changed to director of manufacturing department of China Textile Corporation, 1953 He has been the deputy director general of Qingdao Textile administration since February 2002. Yang Yuelin is a member of the CPC Qingdao Committee of the NLD, a member of the second, third and fourth standing committees of the CPPCC Qingdao Municipal Committee, a representative of the first to third National People's Congress of Shandong Province, a member of the people's Committee of Shandong Province from 1955 to 1958, and a part-time vice chairman of Qingdao Association of science and technology in July 1957.

\subsection{Works of Yang Yuelin}

Yang Yuelin wrote in the preface of "theoretical and practical sizing law" that "there are not many books on sizing", which proves that there are few books on sizing law in the Republic of China. At the beginning of the last century, Percy bean, an Englishman, wrote the chemistry and practice of finishing; a practical treatment on the bleeding \&amp; Finishing of cotton goods for white. There was no Chinese translation of the book. Yang Yuelin named the title of sizing chemistry and practice in his preface. This book is the same as Moriyama Hongzhu's "management of sizing and sizing machine" and Kiyosaki's "Research on warp sizing". Most of the contents are too practical, and the principles of technology are not elaborated in depth, which makes these three books unable to be used as effective education materials. When Yang Yuelin studied in Japan, he had read Machida's "warp sizing", which not only elaborated the theory of cotton sizing, but also elaborated the principle of sizing. For example, the "tindal effect" and other related chemical phenomena are described in detail in "theoretical and practical sizing".

In the theoretical and practical sizing method, there is a large space for the type and proportion of sizing materials. According to different sizing methods, different sizing experiments were carried out on mechanical sizing, pot sizing, winch sizing and bead warp sizing. It can be said that the experiment is sufficient. For the cutin mixed by the pulp, the investigation is also very meticulous: the state, viscosity and properties of the gum. Moreover, the book has summarized a series of working principles that need to be described in the sizing process. As for the overall purpose of sizing, the book has explained as follows: due to the poor cohesion between the fibers of the original yarn and more surface hairiness, it is difficult to weave directly. In order to improve the weavability of the warp on the loom, so that the warp can withstand the repeated friction, stretching, bending and other functions between the warp pad, heald, reed and the warp on the loom without raising or even breaking the ends. This is what we often say. The purpose of warp sizing is to lay down hairiness and enhance wear resistance. It also plays an important role in the innovation of sizing machine. When the book was finished, Yang Yuelin's sizing machine was the double drying cylinder sizing machine widely used in China in the 1950s. This sizing machine is called double drying cylinder sizing machine because it relies on two huge copper surface drying cylinders to dry the wet sizing yarn by dragging the warp sheet. At that time, the name was used: Shifu sizing machine - Lu Shifu was an old engineer of Shanghai Textile Research Institute before his death. In this way, the sizing speed is slow and the sizing elongation is quite large. It has been eliminated. However, it still makes a great contribution to the research of the history of textile science and technology in China.

In the "theoretical and practical sizing law", it also records the size differences between the north and the south. 
This is a very precious record for China, which did not even produce the size workshop in that year. There is a "jigging workshop" in the textile factory in the south, which takes wheat flour as raw material, washes out the "gluten" to obtain wheat starch, and then decomposes the wheat starch through fermentation as the pulp. The "jigging workshop" of North Textile Factory is to make corn starch with corn as raw material, after grinding, extruding and removing impurities such as protein and fat in corn, etc., by a long tank sedimentation method up to tens of meters long. It is also used to decompose corn starch by fermentation. The slurry obtained by this fermentation method, because it still contains a lot of impurities such as protein and fat, has a low degree of decomposition, a large viscosity of the slurry and poor liquidity. This kind of starch film is thick, brittle and hard. It is often used with a variety of auxiliary sizes, such as softener, hygroscopic agent, penetrant, lubricant, preservative and so on. There are as many as 10 kinds of auxiliary sizes used (which can be seen in early textbooks and Literature). In order to produce normally, sizing workshop and cloth machine workshop need to be carried out in high temperature and humidity environment. Therefore, the working conditions of sizing workshop and cloth machine workshop were very poor at that time. It can be seen that in the early days of the founding of the PRC, the working people made great efforts under the guidance of the goal of revitalizing the textile industry.

\section{Yang Yuelin's Driving Force for Domestic Sizing Work}

\subsection{Sizing Method}

"Theoretical and practical sizing science" is an early systematic "sizing book" in China, with more than 300000 words and nearly 100 illustrations. After it was officially published in February 1948, it attracted the general attention of the textile academic circles and gave high praise. It was not only used as teaching materials by professional schools at that time, but also widely used by practical workers in various factories. For example, the "sizing working method" summarized by Qingdao Textile Administration Bureau based on sizing theory was fully promoted in 1953, which ensured the proper sizing moisture and the smooth realization of light sizing, and balanced warp strength. Another example is the method of sizing with "sodium silicate" decomposing agent introduced in the book. The sizing rate is reduced to below 7\%, which not only improves the warp strength, reduces the end breakage of the warp, but also reduces the coal consumption and saves a lot of flour. In October 1954, at the Qingdao national textile technology professional conference of the Ministry of textile industry, vice minister Zhang qinqiu and Secretary General Zhang zesun of the National Committee of China textile trade union affirmed the "sizing work law" and called for its promotion to the whole country. The promotion of sizing working method in Shandong Province is very strong. In the "sizing working method", the whole sizing process is recorded and standardized very accurately, including the working process of sizing, sizing table and so on.

In the early days of the founding of new China, in the "red may" labor competition held by all walks of life, Hao Jianxiu, the value-added lathe worker of Qingdao guomian No.6 factory, created the "Hao Jianxiu work method", which was promoted in the national textile industry as the first scientific work method in the textile industry of new China. Then, Qingdao Textile established "May 1st weaving work law" and "May 3rd preservation work law", which played a huge role in promoting the rapid recovery of Qingdao's economy and the development of the national textile industry in the early period of liberation. Qingdao Textile administration was established in 1953. By 1957, there were 9 cotton textile enterprises, 32 cotton mills, 15 printing and dyeing enterprises and 9 knitting reproduction factories under its jurisdiction. The annual total output value is 540 million yuan, the annual profit is 63.69 million yuan, and the tax is 48.18 million yuan. It made a great contribution to the economic development in the early days of the founding of the people's Republic of China.

In December 1958, Shandong Textile Industry Department was established, and Qingdao Textile Administration Bureau and Qingdao dyeing and weaving Bureau were merged into Qingdao Textile Industry Bureau. In March 1962, Qingdao Municipal Bureau of textile industry and Shandong Provincial Department of textile industry merged to establish Shandong textile industry administration and set up Shandong textile industry administration in Qingdao. By the end of 1965, Qingdao had produced 379900 cotton yarns and 295 million meters of cotton. The total annual output value is 662 million yuan and the annual profit is 129 million yuan.

Qingdao textile, no matter its production scale, technical equipment, management system, technical force, product quality, output value, profits and taxes paid and product export, plays an important role in the national textile industry, thus winning the reputation of "shangqingdao Tianjin". In the 1960s and 1970s, Qingdao Textile delivered a large number of cadres and technical backbones to foreign and domestic textile industries, successively supported the construction of textile industry in Vietnam, Guyana, Cambodia, Pakistan, Nigeria, Zambia and other countries, and supported the new cotton mills in Beijing, Shaanxi, Shanxi, Hebei, Henan, Inner Mongolia, Xinjiang and other places. At the same time, it has also built 15 branches in Zaozhuang, Pingyin, Dezhou, Binzhou, Mengyin, Jining, Linqing, Zhucheng, Linyi, Huimin, Heze, etc. By the end of 1995, Qingdao 
textile has created a total output value of nearly 40 billion yuan for the country and paid 10 billion yuan in profits and taxes.

\subsection{Hao Jianxiu's Spinning Method}

In November 1949, Hao Jianxiu entered Qingdao No.6 cotton textile factory as a nurturing worker. After three months, Hao Jianxiu was appointed as the official shift-a spinner. In the course of her work, in order not to doze off, she constantly stopped the patrol car. During the tour, Hao Jianxiu found that as long as the cleaning work was done well, the yarn breakage would be reduced. Therefore, she carried out several work procedures in an orderly and tense manner, saved time to do more cleaning work, mastered the law of tour, and reduced the number of broken heads. However, Hao Jianxiu's achievements have not been found because the spinning workshop has not yet established the system of weighing the leather roller flower on each stage. In 1950, after the national "red may" labor competition, the spinning workshop of the Sixth cotton textile factory also established a personal white flower weighing record system. Hao Jianxiu's excellent performance and advanced working methods were praised by the factory leaders. She further studied the technology and repeatedly skillfully reduced the operation method of breaking the head. She spent less time every day, which made her famous in the whole factory. From 300 ingots to 400 ingots and 500 ingots, her car checking ability has been improved to 600 ingots, but her white flowers have been kept between $0.2 \%$ and $0.3 \%$. By February, 1951, the average rate of roller flowers was $0.25 \%$, which set a new record of less white flowers for seven consecutive months.

In the early days of the people's Republic of China, inspired by the party's policies, Yang Yuelin, like the majority of textile workers, burst out the enthusiasm and creativity to restore and develop textile production, consciously playing out the advantages of understanding production, management and technology. Under the direct guidance of the Ministry of textile industry and the national textile trade union, he actively participated in the summary and promotion of the "Hao Jianxiu spinning work method". At the same time of popularizing advanced working method, we should constantly improve ourselves. "The working masses are the basic force for the development of textile production. While fully mobilizing the subjective initiative of the masses, the technical managers should change the objective material conditions so that the masses have both the driving force and the scientific spirit," he said Therefore, while promoting the "Hao Jianxiu spinning work method", he seriously led the summary of "weaving work method", "combined rough work method", "leather roller work method" and "machine maintenance work method". The summary and promotion of these working methods not only improved the production level of Qingdao textile industry, but also summarized and promoted the national "May 1 weaving working method" and "May 3 preservation working method", which provided the basis for drafting the "experience exchange meeting of Qinggang pulp" in 1954, enriched the content and made contributions.

\section{References}

Textile Industry Committee. (1955). Hao Jianxiu's work method. Textile Industry Press.

Yang, Y. L. (1948). Discussion on warp sizing. Textile dyeing engineering, 11, 17-21.

Yang, Y. L. (1948). Theoretical and practical sizing. Qingdao Branch of China Textile Association.

Yang, Y. L. (1949). Chen Quzhen invents Quanzhen spinning machine. Southwest Industrial Communication, 3, $40-41$.

Yi, P. C. (2009). Shandong Democratic League Xianda. Qunyan Publishing House.

\section{Copyrights}

Copyright for this article is retained by the author(s), with first publication rights granted to the journal.

This is an open-access article distributed under the terms and conditions of the Creative Commons Attribution license (http://creativecommons.org/licenses/by/4.0/). 